\title{
High Sensitive MEMS Intraocular Capacitive Pressure Sensor (Glaucoma)
}

\author{
Tania Mohammed Abbas \\ Qais Kareem Al-Gayem \\ Department of Electrical Engineering, University of Babylon, Babylon-Iraq \\ Taniamohammed86@gmail.com \\ qaiskareem@yahoo.com
}

\begin{abstract}
Micro Electro Mechanical Systems (MEMS) are a small-scale technology that was largely adopted by the IC industry and applied to miniaturize of all systems (electrical systems, mechanical, optical, fluidic, magnetic, etc.). Minimization has been accomplished with small manufacturing processes. A Capacitive pressure sensor is simply a diaphragm-type device in which the diaphragm displacement is determined by measuring the capacitance change between the diaphragm and a metal plate that is close to it.
\end{abstract}

For this purpose, intraocular pressure sensors are important in detection and treatment of an incurable disease called glaucoma. To improve the sensitivity of the capacitive pressure sensor, low stress doped polysilicon material is used as a biocompatible material. Glaucoma is a group of eye diseases that occurs by high intraocular pressure (IOP). IOP is the pressure exerted by the ocular fluid called aqueous humor (the clear fluid inside the eye) that fills the anterior chamber of the eye

The results Shows the simulated relation between capacitance and pressure for clamped ++ silicon and polysilicon clamped. It can be seen from figure that the initial capacitance for clamped $\mathrm{p}++$ silicon is about $1.81 \mathrm{pF}$ the capacitance varies from 1.81 to $2.162 \mathrm{pF}$ for clamped $\mathrm{p}++$ silicon and clamped polysilicon diaphragm, respectively, so the total variation of the capacitance. This result shows the use of poly silicon material in diaphragm is high sensitivity than the p++ silicon.

Keywords: - Capacitive pressure sensor (Glaucoma), Polysilicon material, P++ silicon.

\section{Introduction}

Many people throughout the world are suffering from irreversible vision loss called glaucoma [1]. Glaucoma is a group of eye diseases that occurs by high intraocular pressure (IOP). IOP is the pressure exerted by the ocular fluid called aqueous humor (the clear fluid inside the eye) that fills the anterior chamber of the eye [2]. Normal intraocular pressure is in the range of 10-21 mmHg [3][4]. In glaucoma patients, when there is no balance between the aqueous outflow and aqueous inflow, then the IOP increases above the normal range. High IOP leads to loss of optic nerve tissue, loss of peripheral vision, and finally blindness if not treated [2]. The condition is painless and direct or indirect pressure measurement is necessary for vision loss detection. Therefore, it is important to have an accurate measurement of the IOP for glaucoma patients [5]. The accuracy of IOP measured by conventional techniques such as Goldman application tonometry depends largely on corneal properties such as central corneal thickness [6]. Another technique called dynamic contour tonometer (DCT) has been introduced [7] that is not affected by central corneal thickness. Different portable to no meters such as Tono-Pen [8], noncontact tonometer have been introduced [9] over the years. However, by the techniques it is not possible to measure the IOP continuously 
reported large fluctuation in diurnal IOP in glaucoma patients that is an important risk factor. Therefore, continuous IOP measurement in glaucoma patients may provide more accurate. For sensor implantation, there are some spatial restrictions in the eye that need to be considered. Different parts of the eye can be used for implants. Implants placed in the anterior chamber of the eye have an additional advantage while the implants placed in the vitreous cavity have a higher risk of infection [4]. Considering the available space in the anterior chamber of the eye, it is better to take advantage of available space to optimize the design [2]. Figure 1 shows option for anterior chamber implants in the eye. The bio telemetric systems are classified into active sensing devices and passive sensing devices [8]. Almost all the devices, both active and passive, used capacitive transducers for pressure sensing for their low power consumption, low noise, high sensitivity, low temperature drift, and good long-term stability. Advances in silicon micromachining techniques have also helped in the miniaturization of the capacitive pressure sensors.

MEMS passive intraocular pressure sensor with $\mathrm{p}++$ silicon diaphragm. The sensor is a simple R-L-C resonant circuit. The resonant circuit consisted of a pressure variable capacitor and an inductor. The capacitor is comprised of a thin flexible diaphragm exposed to the pressure exerted by the eye fluid. Capacitive pressure sensors translate a pressure change into a capacitance variation. Capacitive pressure sensors generally operate by sensing the downward displacement of a thin, flexible conductive membrane (diaphragm) as one of the electrodes, while the other electrode is fixed beneath the membrane. Deformation of the movable part due to applied pressure is sensed and translated into an electrical capacitance change [9].

The paper mainly deals with the capacitive sensor proposed. The main goal is to develop the sensitivity of the capacitive pressure sensor. The future implant will consist of a capacitive pressure sensor connected to a micro coil. Passive LC resonance technique will be used for the continuous wireless monitoring of intraocular pressure. In this paper, first capacitive sensor with clamped $\mathrm{P}++$ silicon diaphragm is investigated and simulated as a main structure. For achieving more sensitive device and reducing the residual stress and stiffness of diaphragm, two steps have been proposed and implemented in the main structure. First low stress doped polysilicon material is used as a biocompatible material instead of $\mathrm{p}^{++}+$silicon.

\section{Pressure sensor structure}

In pressure sensors, pressure is determined by the deflection of the diaphragm due to applied pressure. Figure 1 illustrates cross-section view of the typical pressure sensor with clamped diaphragm. The diaphragm side length is $2 \mathrm{a}$, thickness $\mathrm{h}$, and the thickness of the air gap is d. When exposed to an external uniform pressure $\mathrm{P}$, the diaphragm deflects causing a decrease in the air gap that result in an increase in capacitance between the diaphragm and the back plate. When pressure is withdrawn, the diaphragm moves back to its original position resulting in a decrease in capacitance. For a time-varying incident pressure, the capacitance change follows the same dynamic characteristics of the incident pressure. \{ This change in capacitance is converted into a useful voltage signal using a bias voltage and a charge integrator. $\}$ 
Journal of University of Babylon for Engineering Sciences, Vol. (26), No. (7): 2018.

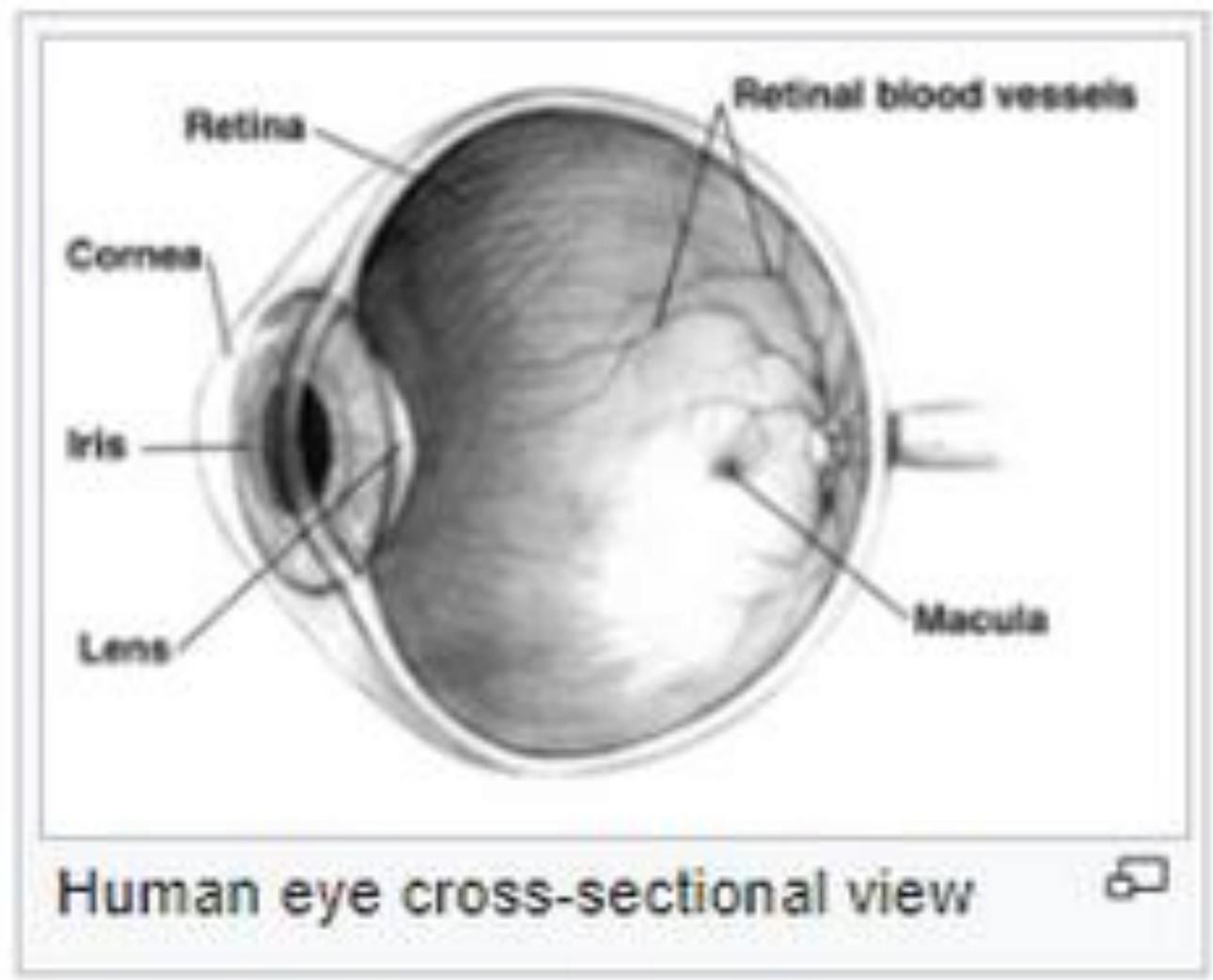

Fig. 1 Option for anterior chamber implant in the eye

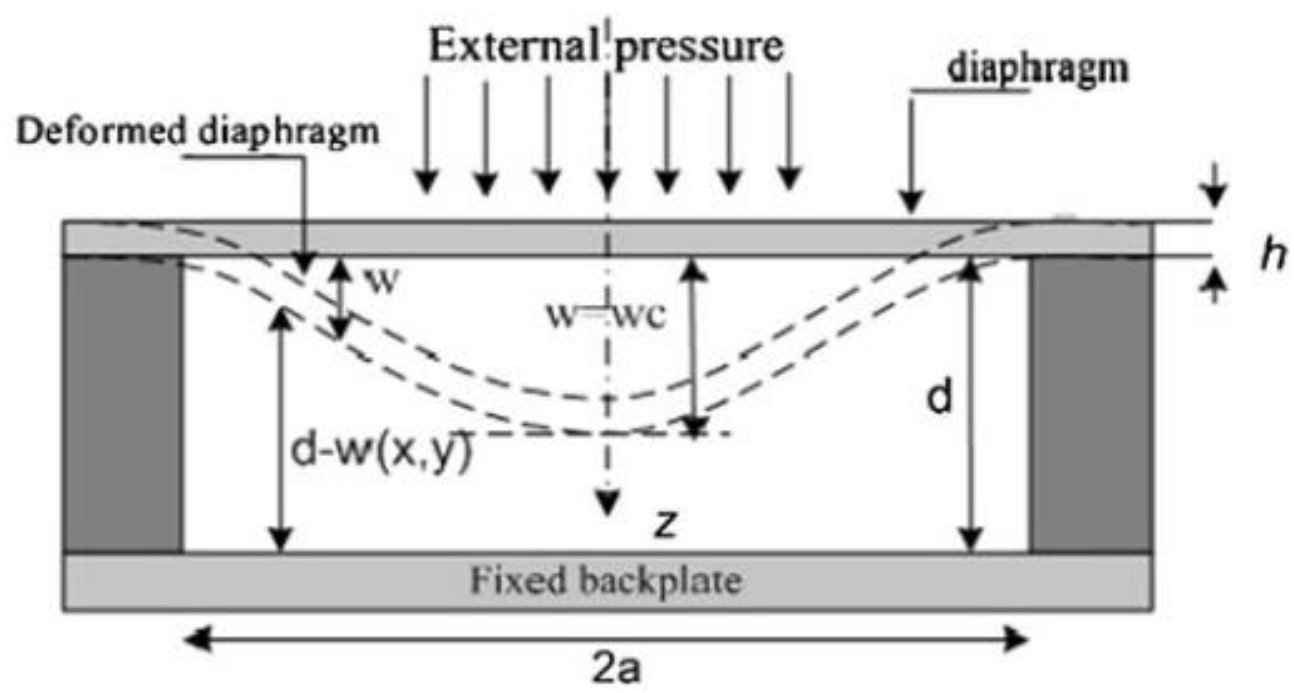

Fig. 2 Cross section view of typical pressure sensor

The Young's modulus and Poisson's ratio of $\mathrm{p}++$ silicon are assumed to be $160 * 10^{\wedge} 9 \mathrm{~Pa}$ and 0.05 , respectively, the thickness of the $0.55 \mathrm{~mm} * 0.55 \mathrm{~mm}$ membrane is $4 \mu \mathrm{m}$, and the height of the air gap is about $1.5 \mu \mathrm{m}$ 


\section{Capacitive Pressure Sensor}

The subject of research is a sensitive membrane of capacitive pressure sensor. Capacitive sensors use an elastic pressure-sensing element in the form of a variable capacitor gap due to displacement or deflection under pressure of membrane-electrode movable relative to the fixed electrode. It means that design of capacitive pressure sensors is flat and cylindrical capacitor. The principle operation of these pressure sensors is based on the change in capacitance of the capacitor, depending on the applied load on one of the electrodes [10].

It is known that the capacity of flat capacitor is directly proportional to the square cover and inversely proportional to the distance between them [11].

$$
\mathrm{C}=\varepsilon 0 \varepsilon \frac{s}{\delta}
$$

\section{Where:}

$\varepsilon 0$ is electric constant of the medium between the plates

$\varepsilon$ is dielectric constant

$S / \delta$ are the area and the distance between the plates.

Sensitive elements of capacitive pressure transducers are membranes and diaphragms, which convert the measured pressure in the movement [12]. The relative capacitance changing in diaphragm membranes is proportional to the measured pressure

$$
\frac{\Delta C}{C}=\frac{R^{\wedge} 2}{8 \delta W} P x
$$

\section{Where:}

$\mathrm{R}$ - Radius of the membrane;

$\mathrm{W}$ - The magnitude of the deflection of the membrane;

$\delta$ - The distance between the membrane and the movable cover in the absence of pressure.

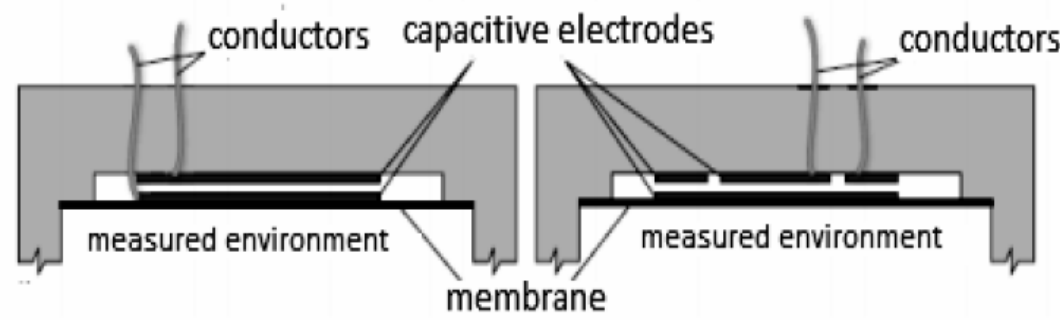

Figure (3): Capacitor pressure sensor [12]

Therefore, to improve properties such as sensor accuracy and increasing the range of measurements necessary to produce sensitive membrane of this size for maximum distance changing between the plates. 
In addition, it necessary to keep in mind the potential dielectric breakdown, when a significant approximation capacitor plates to one another and while appearance of the large stress, which can damage membrane.

The simulation of the MEMS capacitive pressure sensor in touch mode achieves good linearity and large operating pressure range. Intellisuite software is used for modeling and simulating of MEMS capacitive pressure sensor to optimize the design, improve the performance and reduce the time of fabricating process of the device.

Recently MEMS capacitive pressure sensors have gained advantages over piezo resistive pressure sensor due to high sensitivity, low power consumption, invariance of temperature effects. As theses sensors application range is increasing, it is essential to review the technological developments and future scope of MEMS capacitive pressure sensor. [12]

\section{MEMS Capacitive Pressure Sensor Design for High Pressure Applications}

Two plates that can store an electric charge form a capacitor. The charge generates a potential difference, which may be maintained using an external voltage. A capacitive pressure sensor measures a pressure by detecting an electrostatic capacitance change. At least one electrode of the capacitor is on a moving structure. Capacitive sensors have the advantage over the piezo resistive type as they consume less power. However, have a nonlinear output signal and are more sensitive to electromagnetic interference. Capacitive sensors are compatible with most mechanical structures, and they have high sensitivity and low temperature drift. Capacitive pressure sensors have the problem that, they exhibit non-linear relationship between capacitance and displacement. Hence, linearization is an issue in such kind of sensors [12][14].

\section{Performance Parameters}

1. Burst Pressure: This is the maximum pressure that may be applied to the sensor without causing the sensor catastrophic failure [15].

2. Temperature Compensation: The temperature ranges across which the specification values of the pressure sensors are guaranteed, i.e., the measurement error of the pressure sensor will be within a certain bond.

3. Supply Voltage/ Supply Current: The constant supply voltage or constant supply current required to drive pressure sensors.

4. Zero Offset: Zero Offset is the output of a pressure sensor when no pressure is applied. Zero offset is either expanded as percentages of full-scale $\mathrm{o} / \mathrm{p}$.

Zero offset can be easily eliminated during calibration step.

5. Linearity: The maximum deviation of measured output. The non-linearity is addressed by using the best-fit straight-line (BFSL) method.

6. Sensitivity: Sensitivity of a capacitive pressure sensor can be defined as Electrical and mechanical sensitivity. Electrical Sensitivity is defined as the ratio of change in the capacitance to change in the pressure $S c=\frac{\Delta C}{\Delta P}$ terms of voltage it will be the ration of change in voltage to change in pressure.

7. Mathematical Equations to Measure Diaphragm Deflection. 
Typically, the geometries used for the diaphragm design are square, rectangular and circular configurations. In all cases, maximum deflection is observed at the Centre of the plate/diaphragm.

According to the theory of Plates [16, 17-18] by Krigger the equations governing the deflection of plates with pressure acting normal to the plate/diaphragm surface is given by (3)

$$
\frac{\partial^{\wedge} 4 w}{\partial x^{\wedge} 4}+2 \alpha \frac{\partial^{\wedge} 4 w}{\partial x^{\wedge} 2 \partial y^{\wedge} 2}+\frac{\partial^{\wedge} 4 w}{\partial y^{\wedge} 4}=P / D
$$

For maximum deflection at the center of a square plate is given by Equation (4) $\&(5)$

$$
\begin{aligned}
& W \max =0.00674 \frac{p a}{D} \\
& D=\frac{E h^{\wedge} 3}{12\left(1-\gamma^{2}\right)}
\end{aligned}
$$

For circular diaphragm

$$
S c=\frac{\Delta v}{\Delta p}
$$

Mechanical sensitivity is defined as the ratio of change in displacement to change in pressure applied

$$
\begin{aligned}
& S m=\frac{\Delta W}{\Delta P} \\
& W(r)=\frac{P a^{\wedge} 4}{64 D}\left[1-\left(\frac{r}{a}\right)^{2}\right]
\end{aligned}
$$

For rectangular diaphragm

$$
W \max =\alpha \frac{P a^{\wedge} 3}{D} \text { For } \mathrm{a}>\mathrm{b} \text { or } \mathrm{a}<\mathrm{b}
$$

Where

$$
\alpha=1.26 * 10^{-3} * 12\left(1-v^{2}\right)
$$

1) For Square/rectangular diaphragm: $\mathrm{W}$ - is deflection at $(\mathrm{x}, \mathrm{y})$ coordinates, $\mathrm{P}-$ is differential pressure, D - is flexural rigidity, a - is the length of diaphragm, E - is young modulus, $\mathrm{V}-$ is Poisson's ratio and $\mathrm{h}-$ is the thickness of the diaphragm.

2) For circular diaphragm: W(r) is deflection at radial distance $r$ from the Centre of diaphragm, $a$ - is radius of the diaphragm, $r$ - radial distance.

3) For Rectangular diaphragm: $a$ - Length of plate, $b$ - width of the plate, $\alpha$ - numerical factor depending on the ratio $\mathrm{b} / \mathrm{a}$ or $\mathrm{a} / \mathrm{b}$.

\section{Specifying physics}

After producing the 3-D structure of the capacitive pressure sensor, the boundary conditions of electromechanical system have been specified for the next the physics feature settings and added to the model. These include the pressure forces acting on the sensor, the applied sense voltage, and other appropriate boundary conditions.

In the electro mechanics interface, the Linear Elastic Material is used to solve the equations of structural mechanics only. 
Apply a boundary load is needed to represent the pressure acting on the top surface of the diaphragm. The moving mesh boundary conditions need to be applied on boundaries where the air domain deforms and where the default electromechanical interface boundary condition does not apply. Three material were used in the design, the first martial was silicon

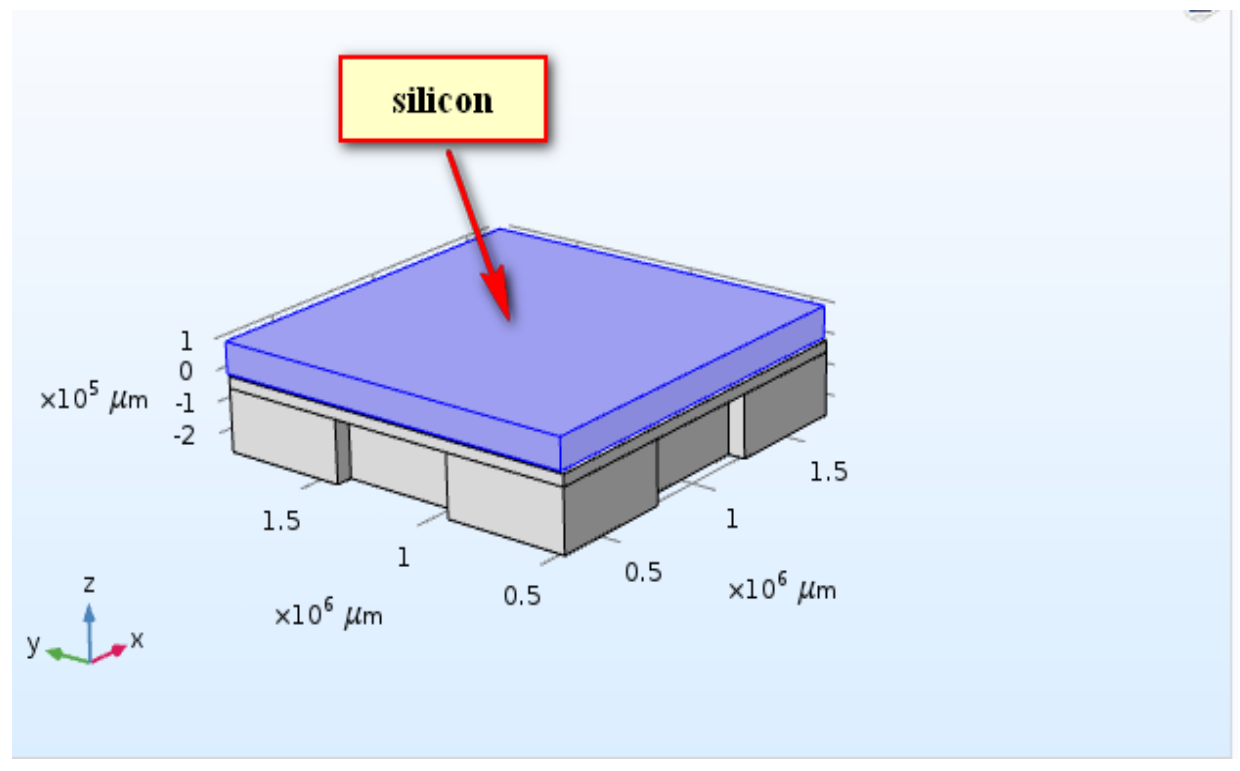

Figure (4): shows the silicon layers in the model

Table (1) silicon specification

\begin{tabular}{|c|c|c|c|}
\hline Property & Name & Value & Unit \\
\hline Young modelu & $\mathrm{E}$ & 170 & $\mathrm{Gpa}$ \\
\hline Passion ratio & $\mathrm{nu}$ & .06 & 1 \\
\hline Density & rho & 2330 & $\mathrm{Kg} / \mathrm{m}^{\wedge} 3$ \\
\hline $\begin{array}{c}\text { Coefficient of thermal } \\
\text { expression }\end{array}$ & elpha & 11.7 & 1 \\
\hline
\end{tabular}

The second material used in model is polysilicon in table (2)

\begin{tabular}{|c|c|c|c|}
\hline Property & Name & Value & Unit \\
\hline Relative permittivity & epsilon & 4.5 & 1 \\
\hline Electric conductivity & Sigma & Sigma & $\mathrm{S} / \mathrm{m}$ \\
\hline $\begin{array}{c}\text { Coefficient of thermal } \\
\text { expansion }\end{array}$ & alpha & Alpha & $1 / \mathrm{k}$ \\
\hline $\begin{array}{c}\text { Heat capacity at } \\
\text { constant pressure }\end{array}$ & $\mathrm{Cp}$ & 678 & $\mathrm{~J} /(\mathrm{K} . \mathrm{Kg})$ \\
\hline Dencity & Rho & 2330 & $\mathrm{Kg} / \mathrm{m}^{\wedge} 3$ \\
\hline Thermal conductivity & $\mathrm{K}$ & $\mathrm{T}$ & $\mathrm{W}\left(\mathrm{m}^{*} \mathrm{k}\right)$ \\
\hline Young modelu & $\mathrm{E}$ & $169 \mathrm{e} 9$ & $\mathrm{~Pa}$ \\
\hline Passion ratio & $\mathrm{nu}$ & 0.22 & 1 \\
\hline Reference resistivity & rho0 & $2 \mathrm{e}-5$ & $\Omega . \mathrm{m}$ \\
\hline $\begin{array}{c}\text { Resistivity temperature } \\
\text { coeffiecient }\end{array}$ & alpha & $1.25 \mathrm{e}-3$ & $1 / \mathrm{k}$ \\
\hline Reference temperture & Tref & 298.15 & $\mathrm{~K}$ \\
\hline
\end{tabular}


Journal of University of Babylon for Engineering Sciences, Vol. (26), No. (7): 2018.

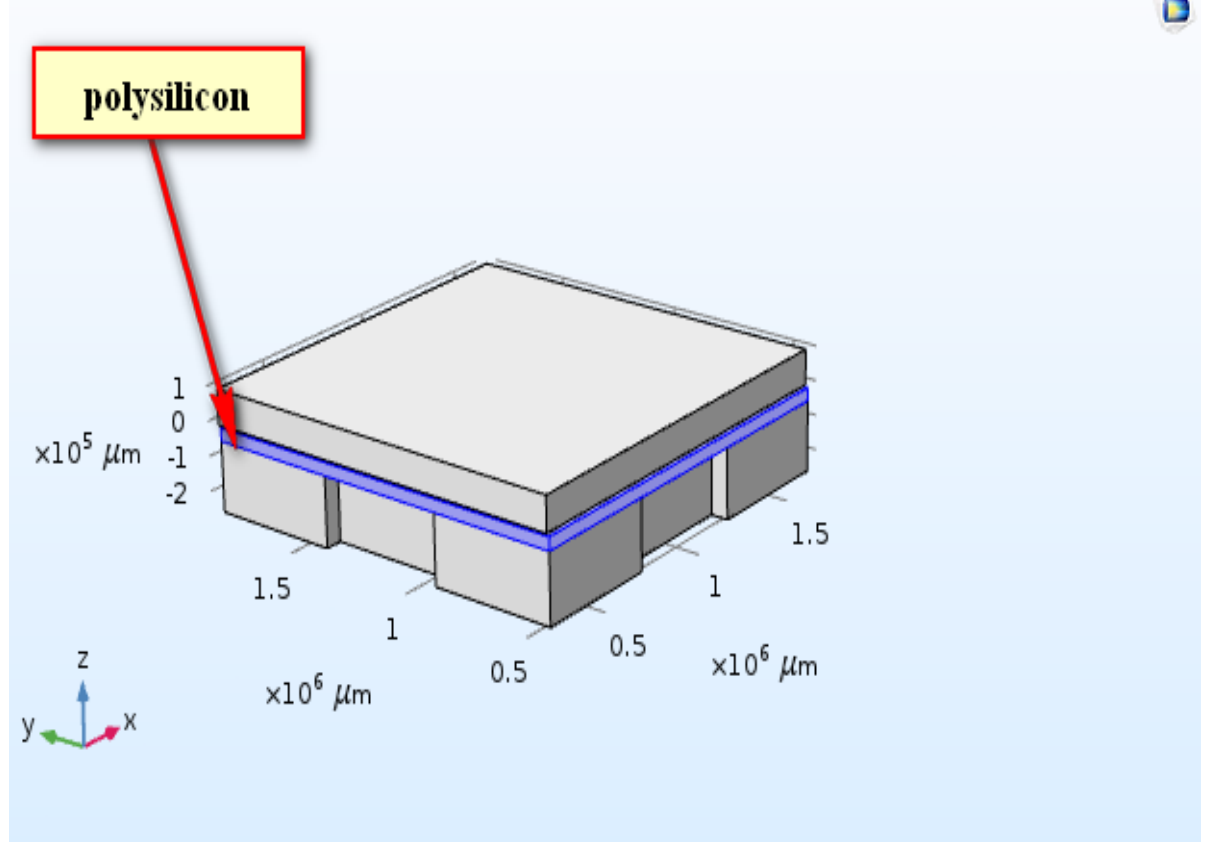

Figure (5) polysilicon layer

The last material used is Steel AISI 4340.1 and it is specification illustrated in table (3)

Table (3) Steel AISI 4340.1specifications

\begin{tabular}{|c|c|c|c|}
\hline Property & Name & Value & Unit \\
\hline Coefficient of thermal expansion & alpha & $12.3 \mathrm{e}^{\wedge}-6$ & $1 / \mathrm{k}$ \\
\hline Density & rho & 7850 & $\mathrm{Kg} / \mathrm{m}^{\wedge} 3$ \\
\hline Young modulus & $\mathrm{E}$ & $205 \mathrm{e}^{\wedge} 9$ & $\mathrm{pa}$ \\
\hline Passion ratio & $\mathrm{nu}$ & 0.28 & 1 \\
\hline Relative permittivity & $\mathrm{mur}$ & 1 & 1 \\
\hline Electric conductivity & sigma & $4.023 \mathrm{e}^{\wedge} 6$ & $\mathrm{~S} / \mathrm{m}$ \\
\hline Heat capacity and constant pressure & $\mathrm{cp}$ & 475 & $\mathrm{~J} /(\mathrm{Kg} . \mathrm{K})$ \\
\hline Relative permittivity & epsilon & 1 & 1 \\
\hline Thermal conductivity & $\mathrm{k}$ & $44.5 \mathrm{ta}$ & $\mathrm{w} /(\mathrm{m} . \mathrm{k})$ \\
\hline
\end{tabular}

\section{Meshing}

After defining the electromechanical system with their constants and the physical constraints, the next process called meshing. Table (4) specifies the number of mesh elements at different meshing and figure (6) shows the model after meshing.

Table (4) Number of mesh elements on different meshing

\begin{tabular}{|c|c|c|c|}
\hline Mesh & Normal & Finer & Extra coarse \\
\hline Number of mesh element & 7971 & 25642 & 1070 \\
\hline
\end{tabular}


Journal of University of Babylon for Engineering Sciences, Vol. (26), No. (7): 2018.

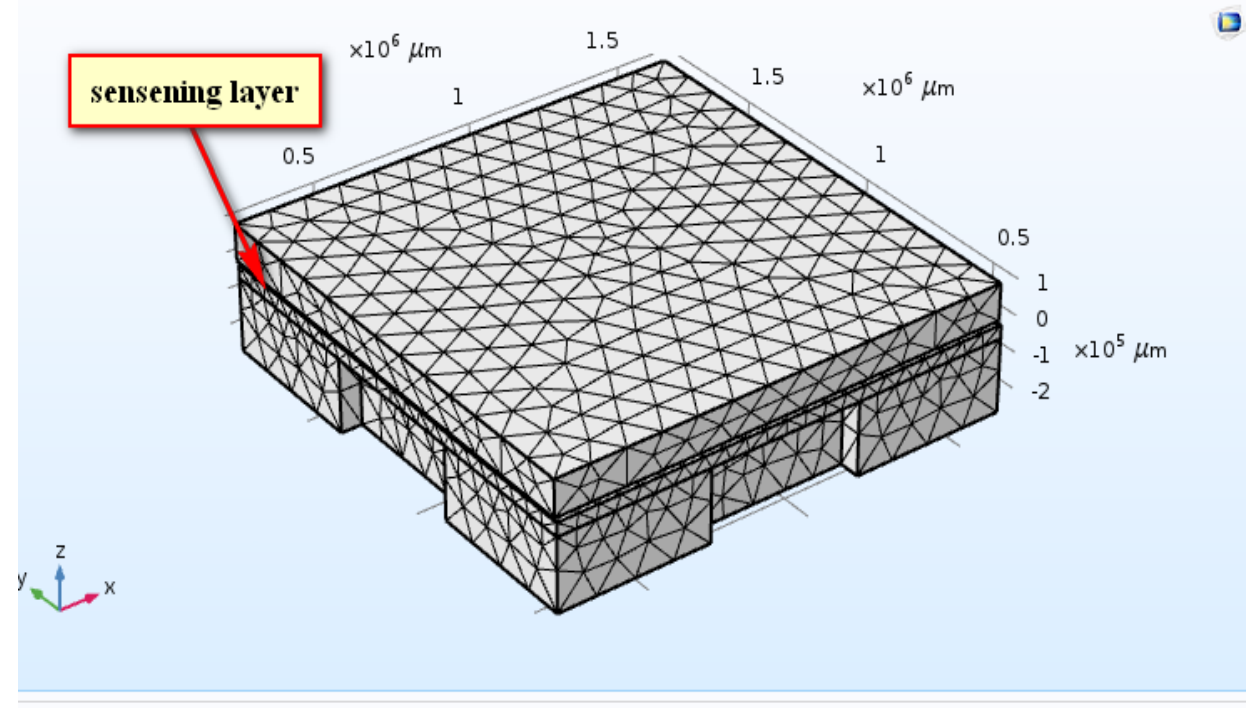

Fig (6): The model after meshing

The darker section is the sensing part of model

\section{Results and discussion}

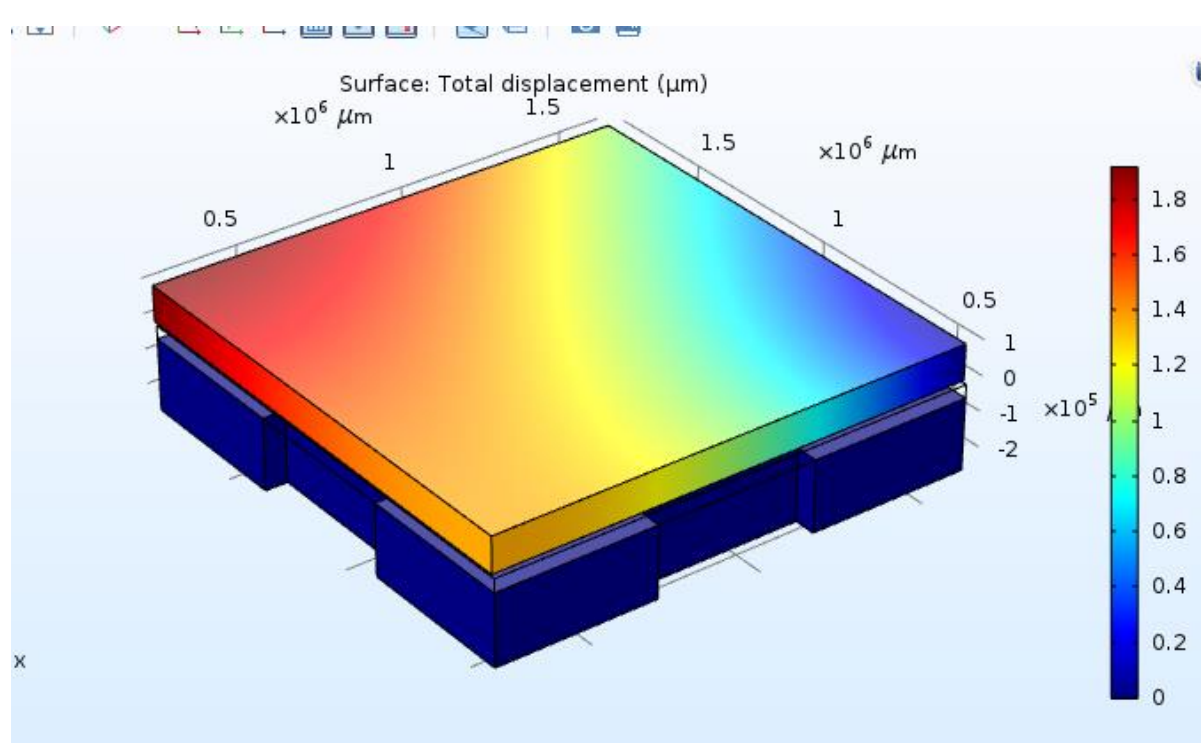

Fig (7) Total displacement of model

After the meshing, the model was computed where figure (7) shows the displacement of the structure distributed due to an applied pressure when packaging stresses are also included in the model. In addition, reach high displacement is $1.8 \mu \mathrm{m}$ 
Journal of University of Babylon for Engineering Sciences, Vol. (26), No. (7): 2018.

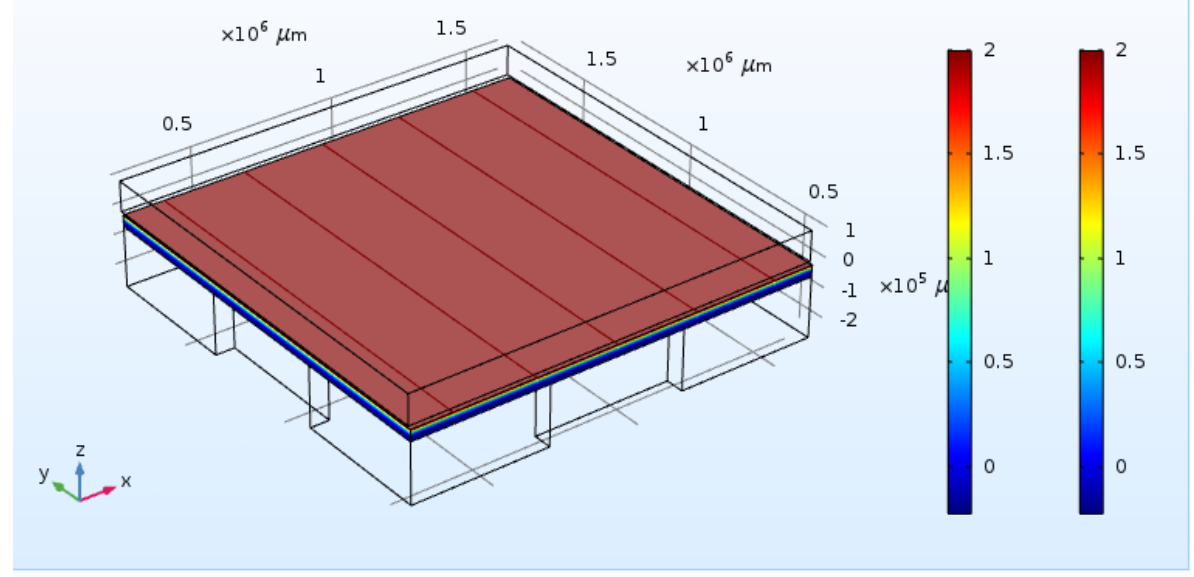

Fig (8): The electric potential of sensor

Fig (8) shows the electrical potential distributed the potential has become uniform as a result of the pressure-induced deformation of the diaphragm.

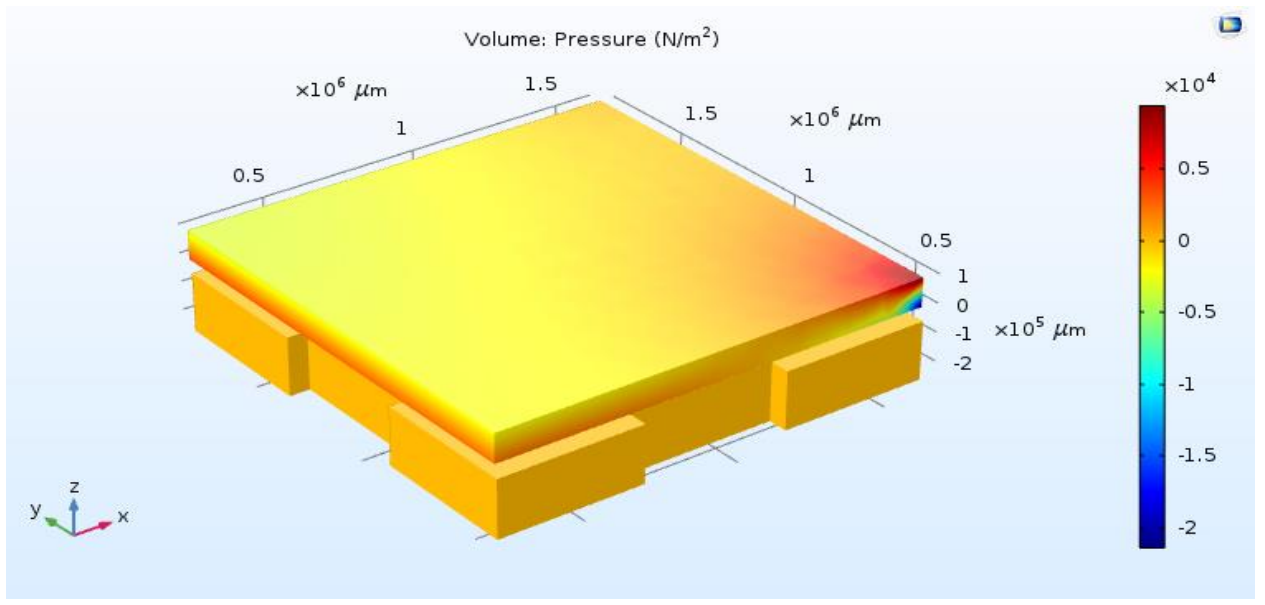

Fig (9) pressure of sensor

In figure (9) the pressure distribution is shown where the high level at the diaphragm, reach $5 \mathrm{kPa}$ because the polysilicon material has strong influence on the mechanical sensitivity, low stress compared to other materials. High-temperature annealing of a low-pressure chemical vapor deposition (LPCVD) of polysilicon thin film that is ion implanted with phosphorous can confine the residual stress 
Journal of University of Babylon for Engineering Sciences, Vol. (26), No. (7): 2018.

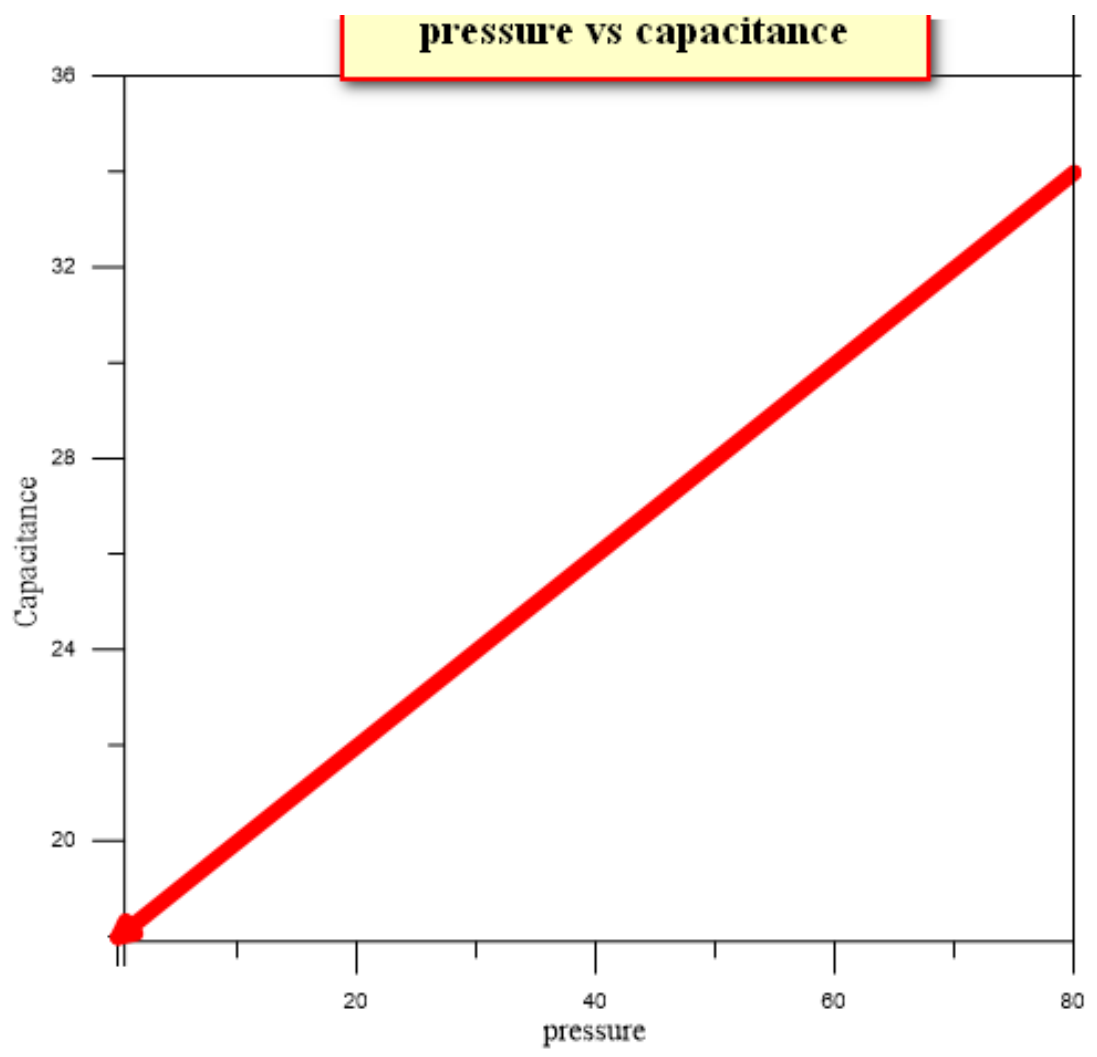

Fig (10): Pressure vs capacitance

In fig (10) shows the simulated relation between capacitance and pressure for polysilicon clamped. It can be seen from figure that the initial capacitance for clamped diaphragms are about3.1 pF. As pressure applies from 0 to $80 \mathrm{mmHg}$, the capacitance varies to $3.1 \mathrm{pF}$ from $1.81 \mathrm{pF}$ The sensitivity of capacitive pressure sensor can be calculated using Eq.

$$
\mathrm{S}=\frac{\Delta C}{C 0 P}
$$

Where $\Delta C$ is the capacitance changes, $\mathrm{C} 0$ is initial capacitance and $\mathrm{P}$ is applied pressure. Using Eq. (3.21), the slope of the curve shows the sensitivity of the pressure sensor. in this case if the diaphragm is replaced by the silicon ++ the sensitivity of poly silicon is the best sensitivity 


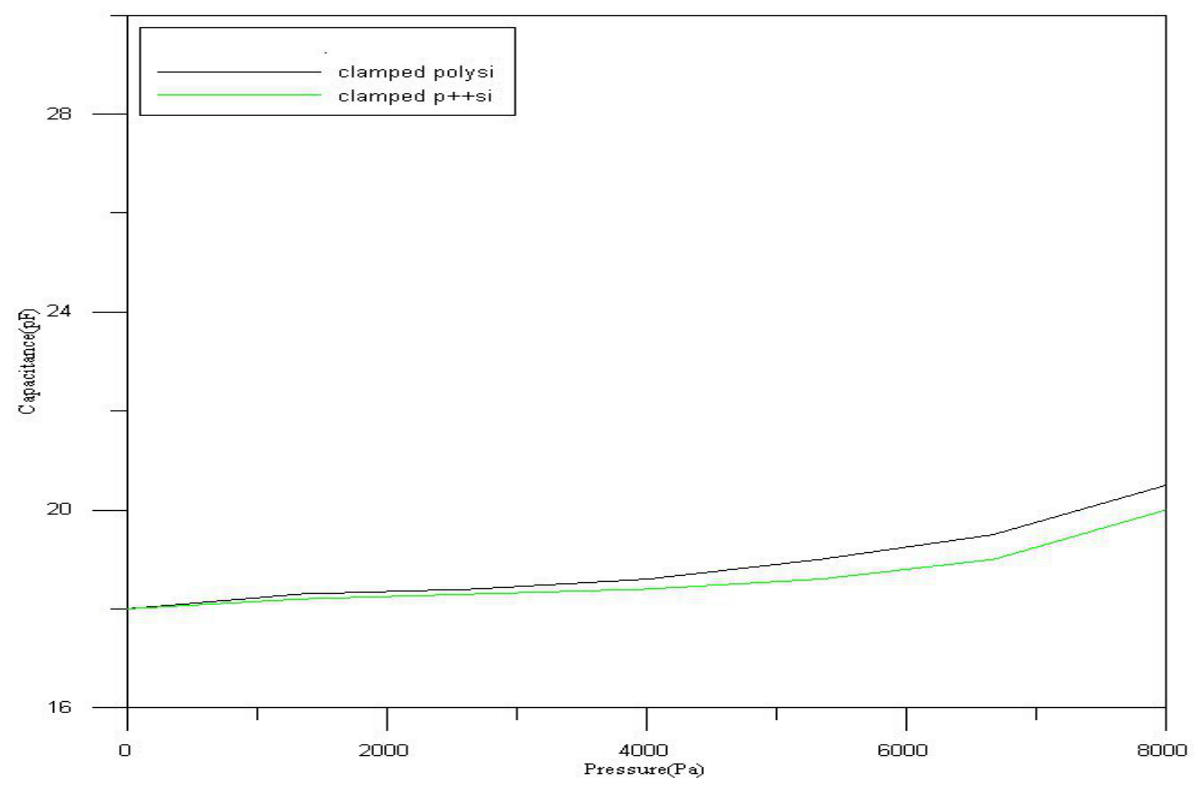

Figure (11) capacitive vs pressure compare between poly silicon and $p++$ silicon

Shows the simulated relation between capacitance and pressure for clamped $\mathrm{p}++$ silicon and polysilicon clamped. It can be seen from figure that the initial capacitance for clamped $\mathrm{p}++$ silicon is about $1.81 \mathrm{pF}$ the capacitance varies from 1.81 to $2.162 \mathrm{pF}$ for clamped $\mathrm{p}++$ silicon and clamped polysilicon diaphragm, respectively, so the total variation of the capacitance

\section{Conclusions}

$3 \mathrm{D}$ capacitive pressure sensor is designed simulated to monitor the eye pressure. Increase the eye pressure causes damaging the optic nerves, which sometimes lead to the blind (glaucoma). In the model design, the polysilicon has been used as a material in the diaphragm to increase the sensitivity of the sensor. The result have been compared with a model that silicon ++ in the diaphragm material where a significant increase in sensitivity has been obtain when the polysilicon was employed in the diaphragm.

\section{References}

[1] Meng E., Chen PJ, Rodger D., Tai YC, Humayun M., Implantable parylene MEMS for glaucoma therapy. In: Proceedings of the third annual international IEEE EMBS special topic conference on microtechnologies on medicine and biology, 2005.

[2] Katuri KC, Asrani S, Ramasubramanian MK, Intraocular pressure monitoring sensors. IEEE Sens 8(1):12-19, 2008.

[3] Tielsch JM, Katz J., Singh K., Quigley HA, Gottsch JD, Javitt J,Sommer A., A population-based evaluation of glaucoma screening: the Baltimore eye survey. Am J Epidemiol 134(10):1102-1110, 1991.

[4] Titcomb L., Treatment of glaucoma: part 1. Pharmaceutical J263 (7060):324-329, 1991.

[5] Katuri KC, Ramasubramanian MK, Asrani S., A surface micromachined capacitive pressure sensor for intraocular pressure measurement. In: IEEE ASME international 
Journal of University of Babylon for Engineering Sciences, Vol. (26), No. (7): 2018.

conference on mechatronics and embedded systems and applications, pp 149-154, 2010 .

[6] Moses RA, The Goldmann applanation tonometer. Am J Ophthalmol 46(6):865$869,1958$.

[7] Schneider E., Grehn F., Intraocular pressure measurementcomparison of dynamic contour tonometry and Goldman applanation tonometry. J Glaucoma 15(1):2-6, 2006.

[8] Moseley MJ, Non-contact tonometry. Ophthalmic Physiol Opt 15(2):35-37, 1995.

[9] Frenkel R., Hong Y., Shin D., Comparison of Tono-Pen to the Goldmann applanation tonometer. Arch Opthalmol 106(106): 750-753, 1998.

[10] Zhou MX, Huang QA, Qin M, Zhou W, A novel capacitive pressure sensor based on sandwich structures. J Micro electromech Sys t 14(6):1272-1282, 2005.

[11] Bolton W., 2006. Capacitance. Engineering science (p. 161). Oxford: Newnes

[12] Martinez L., Giannetti R., Rodriquez M., Design of a system for continuous intraocular pressure monitoring. In: Instrumentation and measurement technology conference, Como, Italy, 2004.

[13] Bian Tian et al., Fabrication and Structural Design of Micro Pressure Sensors for Tire Pressure Measurement Systems (TPMS), Sensors, 9, 2009.

[14] Kaustubh Ramesh Bhate, Design and Fabrication of a MEMS Pressure Sensor and Developing a Release Protocol for MEMS, Thesis, NC State University, 2002.

[15] Bhat K. N., Nayak M. M., MEMS Pressure Sensor-An overview of challenges in 'Technology and Packaging', Journal of ISSS, Vol. 2, No. 1, pp. 39-71, March 2013.

[16] Timoshenko S., Woinowsky-Krigger S., Theory of Plates and Shells, Mc. GrawHill, pp. 13, 105,202, 1959.

[17] Anil Sharma, Jawar Singh, Design and Analysis of High Performance MEMS Capacitive Pressure Sensors for TPMS, in Proceedings of the International Conference on Control, Automation, Robotics and Embedded Systems (CARE), pp. $1-5,2013$.

[18] Madhurima Chatopadhyay, Deborshi Charkraborty, A New Scheme for Determination of Respiration Rate in Human being using MEMS Based Capacitive Pressure Sensor: Simulation Study, in Proceedings of the 8th International Conference on Sensing Technology, 2-4 Sep. Liverpool, UK,pp. 236-240, 2014. 


\section{الحساسية العالية للأظظة الاكترونية و الكهربائية للضغط داخل العين \\ حساس الضغط السعوي (مرض زرق العين)

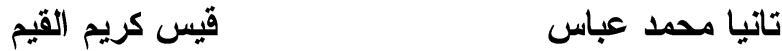 \\ قسم العندسة الكهريائية، كلية العندسة، جامعة بابل، بابل، العراق}

qaiskareem@yahoo.com_ Taniamohammed86@gmail.com

الخلاصة

الأنظمة الميكانيكية الكهرو ميكانيكية الدقيقة(MEMS) هي تقنية صغيرة الحجم تم تبنيها بثكل كبير من

قبل صناعة الدوائر المتكاملة (IC) وتطبيقها على تصغير جميع الأنظمة (الأنظمة الكهربائية والميكانيكية

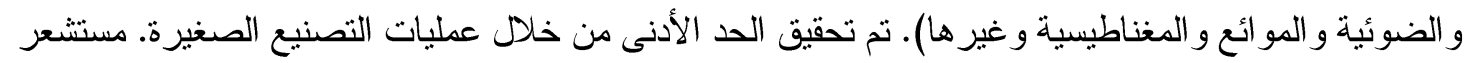

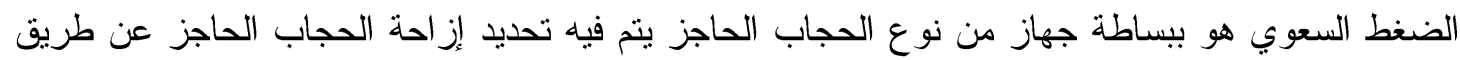
قياس تغير السعة بين الحجاب الحاجز ولوحة معدنية قريبة منه.

لهذا الغرض، وأجزة استثعار الضغط داخل العين مهمة في الكثف عن وعلاج مرض عضال يسمى

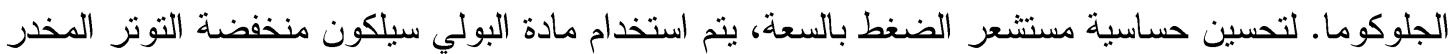

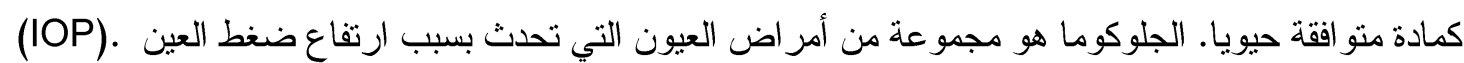
IOP

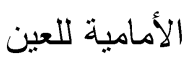

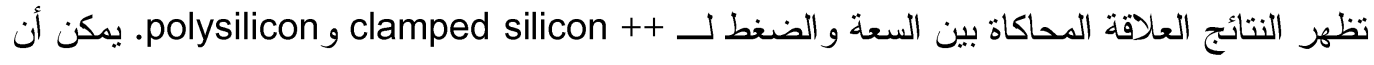

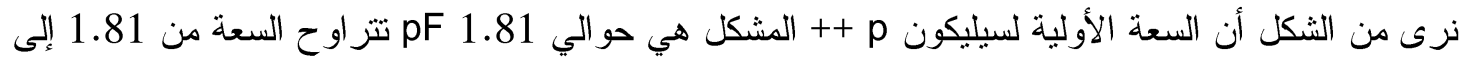

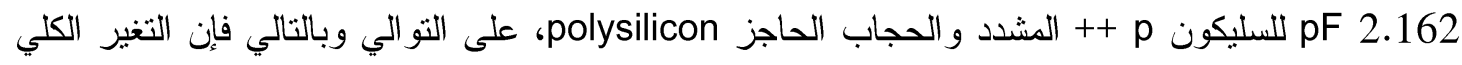

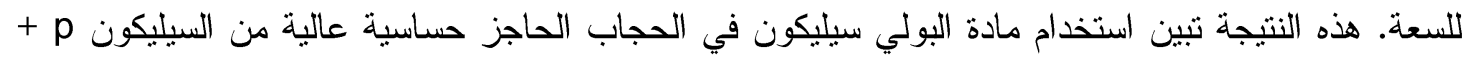
الكلمات المفتاحية: - مرض الزرق العين (الكلوكوما)، ارتفاع ضغط اداخل العين، بولي سيليكون المادة الأولى وسليكون ++. 